\title{
KEMAMPUAN PEDAGOGICAL CONTENT KNOWLEDGE CALON GURU BIOLOGI MENYUSUN RPP PADA PRAKTIK MICROTEACHING
}

\author{
Eka Ariyati \\ Prodi Pendidikan Biologi FKIP Universitas Tanjungpura \\ Jalan Prof. Dr. Hadari Nawawi Pontianak \\ e-mail: eka.ariyati@fkip.untan.ac.id
}

\begin{abstract}
Abstrak
Salah satu faktor pendukung keberhasilan kegiatan pembelajaran adalah adanya guru. Oleh karenanya mahasiswa calon guru harus dilatihkan kemampuan Pedagogical Content Knowledge (PCK). Penelitian bertujuan untuk mengetahui kemampuan PCK calon guru Biologi dalam menyusun RPP pada praktik pembelajaran mikro (microteaching). Jenis penelitian yang digunakan adalah kuantitatif dengan metode deskriptif. Subjek penelitian adalah mahasiswa calon guru Biologi Prodi Pendidikan Biologi FKIP Untan TA 2016/2017 yang sedang praktik microteaching berjumlah 8 orang. Teknik pengumpulan data dengan dokumentasi RPP yang telah dibuat oleh mahasiswa calon guru biologi. Hasil penelitian menunjukkan bahwa kemampuan PCK mahasiswa calon guru biologi dalam menyusun RPP termasuk kategori baik dengan nilai rata-rata kemampuan CK sebesar 70,83\% (baik), kemampuan PK sebesar 75,70\% (baik), dan kemampuan PCK sebesar 66,67\% (baik).
\end{abstract}

Kata Kunci: pedagogical content knowledge, RPP, microteaching.

\begin{abstract}
One of the factors supporting the success of learning activities is the presence of teachers, therefore the teacher candidates must be trained about Pedagogical Content Knowledge (PCK). This study aimmed at determining PCK ability of biology teachers candidate in preparing lesson plan in micro-learning practice (microteaching). The type of research used was qualitative with descriptive method. Subjects in this study were eight biology teacher candidates in Biology Education Program at FKIP Universitas Tanjungpura TA 2016/2017 who were practicing microteaching. Data collection techniques was lesson plan documentation. The result of this research shows that the PCK scores of biology teacher candidate in preparing lesson plan is in good category, with result of CK score percentage $70.83 \%$ (good), result of PK score percentage $75.70 \%$ (good), and result of PCK score percentage $66.67 \%$ (good).
\end{abstract}

Keywords: pedagogical content knowledge, lesson plan, microteaching.

\section{PENDAHULUAN}

Kemampuan seorang guru dalam merancang dan menyusun perencanaan yang tertuang dalam rencana pembelajaran merupakan salah satu faktor yang mendukung keberhasilan proses pembelajaran. Peraturan Pemerintah Nomor 19 
tahun 2005 yang berkaitan dengan standar proses, dimana mengharapkan guru dapat mengembangkan perencanaan pembelajaran.

Hakekatnya, bila suatu kegiatan direncanakan lebih dahulu, maka tujuan dari kegiatan tersebut akan lebih terarah dan lebih berhasil. Itulah sebabnya seorang guru harus memiliki kemampuan dalam merencanakan pengajaran. Pada kegiatan merencanakan yaitu pembuatan rencana pelaksanaan pembelajaran (RPP) tentunya guru harus merancang bagaimana pelaksanaan kegiatan pembelajaran yang akan dilaksanakan di dalam kelas nantinya, mulai dari merumuskan indikator, menentukan tujuan pembelajaran, menentukan strategi apa yang akan digunakan dalam pembelajaran seperti penggunaan metode atau model, sampai dengan merumuskan instrumen penilaian. Menurut Anwar (2014) untuk menjadi seorang guru yang terampil dan dapat mengajar dengan efektif, calon guru tidak hanya sekedar menguasai materi atau konten serta strategi mengajar saja, namun juga harus memiliki pemahaman dan kemampuan khusus untuk memadukan materi, kurikulum, strategi pembelajaran termasuk siswanya, Hal tersebut dapat dicapai salah satunya dengan memahami Pedagogical Content Knowledge (PCK).

Menurut Loughran, et al. (2006) PCK merupakan suatu konstruksi akademik yang mendeskripsikan suatu ide yang mampu membangkitkan minat untuk untuk mempelajari sesuatu. Pengertian lain menunjukkan bahwa PCK adalah suatu cara untuk memahami hubungan yang kompleks antara mengajar dan konten yang diajarkan melalui penggunaan pendekatan mengajar yang spesifik. Berdasarkan pendapat tersebut, dapat dikatakan bahwa PCK merupakan integrasi antara pengetahuan materi (content knowledge) dengan pedagogical knowledge yang dimiliki guru untuk melakukan kegiatan pembelajaran. Dengan demikian, di dalam PCK berisi pengetahuan awal siswa, penyajian materi, strategi pembelajaran, dan materi kurikulum serta fokus kurikulum. Hamidah, dkk. (2011) menyatakan bahwa PCK penting untuk diteliti karena merupakan keahlian khusus dari seseorang yang mengajar yang dipengaruhi oleh konteks, isi dan pengalaman. 
Sedangkan Rosnita (2011) mengungkapkan bahwa PCK adalah salah satu standar penyiapan calon guru.

Kemampuan PCK yang baik pada mahasiswa calon guru, salah satunya terlihat dari kemampuan mahasiswa menyusun RPP. Namun dari hasil penelitian pendahuluan, ditemukan bahwa kompetensi mahasiswa calon guru Biologi dalam menyusun RPP masih kurang. Terungkap bahwa sebagian besar mahasiswa calon guru Biologi masih kesulitan dalam menjabarkan materi ajar sesuai dengan tujuan dan kesulitan dalam menyusun langkah pembelajaran.

Mata kuliah Microteaching merupakan mata kuliah wajib bagi mahasiswa semester VI yang sudah lulus mata kuliah Telaah Kurikulum, Strategi Belajar Mengajar, dan Evaluasi Proses Hasil Belajar. Hal tersebut dimaksudkan agar mahasiswa bisa meramu dan merancang pembelajaran Biologi dengan baik. Melalui kegiatan microteaching diharapkan mahasiswa calon guru dapat menyusun RPP dan melaksanakan pembelajaran sesuai dengan RPP yang telah disusunnya. Keberhasilan dari perkuliahan akan menjadi bekal mahasiswa dalam melaksanakan PPL-2 di sekolah yang sesungguhnya.

Berdasarkan uraian permasalahan, diperlukan penelitian mengenai kemampuan Pedagogical Content Knowledge (PCK) calon guru Biologi dalam menyusun Rencana Pelaksanaan Pembelajaran (RPP) pada perkuliahan Microteaching tahun akademik 2016/2017. Hasil penelitian diharapkan dapat menambah pengetahuan tentang ilmu kependidikan mengenai kemampuan pedagogical content knowledge dalam menyusun RPP dan sebagai bahan evaluasi untuk perkuliahan prasyarat microteaching.

\section{METODE}

Jenis penelitian adalah penelitian kuantitatif. Metode penelitian adalah deskriptif dengan tujuan mendeskripsikan dan menginterpretasi data atau kondisi tertentu sehingga tidak ada perlakuan yang dikendalikan. Subjek penelitian adalah 8 orang mahasiswa Pendidikan Biologi yang mengambil mata kuliah 
Microteaching pada semester genap 2016/2017. Alat pengumpul data menggunakan lembar identifikasi (observasi), sedangkan teknik pengumpulan data yang digunakan untuk mengumpulkan data hasil kegiatan mahasiswa berupa RPP adalah dokumentasi. Analisis data dilakukan secara deskriptif dengan persentase dan dikategorikan berdasar kriteria interpretasi skor yang diperoleh (Widiyoko, 2013).

Tabel 1 Kriteria Interpretasi Skor

\begin{tabular}{cc}
\hline Rentang & Kategori \\
\hline$\leq 20 \%$ & Sangat Kurang (SK) \\
$>21 \%-\leq 40 \%$ & Kurang (K) \\
$>41 \%-\leq 60 \%$ & Cukup (C) \\
$>61 \%-\leq 80 \%$ & Baik (B) \\
$\geq 81 \%$ & Sangat Baik (SB) \\
\hline
\end{tabular}

\section{HASIL DAN PEMBAHASAN}

Data Pedagogical Content Knowledge (PCK) dalam penelitian meliputi kemampuan CK, PK, dan PCK calon guru Biologi dalam menyusun RPP. Subjek yang diteliti sebanyak 8 orang mahasiswa yang mengikuti perkuliahan microteaching pada TA 2016/2017.

\section{Kemampuan CK calon guru biologi}

Kemampuan CK adalah kemampuan dasar guru dalam menguasai materi pelajaran, yang diukur adalah pengetahuan tentang konsep materi, meliputi: (1) kesesuaian materi, (2) keluasan dan kedalaman materi, dan (3) pengembangan 
materi. Adapun data hasil CK calon guru Biologi di FKIP Untan dalam menyusun RPP di sajikan pada tabel berikut.

Tabel 2 Data Kemampuan CK Calon Guru Biologi dalam Menyusun RPP

\begin{tabular}{lcc}
\hline \multicolumn{1}{c}{ Penilaian } & \% & Kategori \\
\hline Kesesuaian materi & 75 & Baik \\
Keluasan dan kedalaman materi & 62,5 & Baik \\
Pengembangan materi & 75 & Baik \\
\hline \multicolumn{1}{c}{ Rata-rata } & $\mathbf{7 0 , 8 3}$ & Baik \\
\hline
\end{tabular}

Berdasarkan data pada Tabel 2, rata-rata kemampuan CK calon guru Biologi adalah 70,83\% dengan kategori baik. Artinya pengetahuan konsep materi mahasiswa baik. Pada indikator kesesuaian materi diperoleh skor sebesar 75\% (baik). Hal tersebut berarti bahwa mahasiswa calon guru Biologi mampu menyesuaikan materi dengan kompetensi dasar (KD), materi dengan indikator, maupun materi dengan tujuan pembelajaran.

Indikator keluasan dan kedalaman materi memperoleh skor terendah yaitu 62,5 (baik). Secara keseluruhan, mahasiswa calon guru mampu menyusun materi sesuai jenjang sekolah (SMP atau SMA) dan mampu menjabarkan materi sesuai KD. Namun, masih ditemukan mahasiswa calon guru yang kesulitan memberikan contoh dari kehidupan sehari-hari atau membuat analogi saat menyajikan materi dalam proses pembelajaran. Sebagaimana yang diungkapkan Hamzah (2008) bahwa seorang guru harus mampu menjabarkan atau menyajikan materi yang menarik didepan siswa, salah satunya dengan memberikan contoh dalam kehidupan sehari-hari atau yang kontekstual.

Pengembangan materi yang disusun atau dibuat mahasiswa calon guru Biologi memperoleh skor $75 \%$ (baik). Hal tersebut karena mahasiswa sudah menggunakan beberapa buku referensi untuk mengembangkan materinya. Pengembangan materi dilihat dari sumber belajar yang mahasiswa gunakan untuk 
memperkaya pengetahuan sekaligus kemampuan mahasiswa menyajikan pengembangan materi sesuai tujuan yang diharapkan.

\section{Kemampuan PK Mahasiwa Calon Guru Biologi}

Kemampuan PK merupakan cara dan proses mengajar yakni kemampuan dalam mengelola kelas, tugas, perencanaan, dan pelaksanaan pembelajaran. Dalam penelitian yang diukur adalah: (1) pemilihan metode/model, (2) penggunaan metode/model, (3) jenis media pembelajaran, (4) pemilihan media sesuai kegiatan pembelajaran, (5) menyusun alat evaluasi, dan (6) pemilihan ranah penilaian. Adapun data hasil PK calon guru biologi di FKIP Untan dalam menyusun RPP di sajikan pada tabel berikut.

Tabel 3 Data Kemampuan PK Calon Guru Biologi dalam Menyusun RPP

\begin{tabular}{|c|c|c|}
\hline Penilaian & $\%$ & Kategori \\
\hline Pemilihan metode/model & 91,67 & Sangat Baik \\
\hline Penggunaan metode/model & 75,00 & Baik \\
\hline Jenis media pembelajaran & 58,33 & Cukup \\
\hline Pemilihan media sesuai kegiatan pembelajaran & 87,50 & Sangat Baik \\
\hline Menyusun alat evaluasi & 79,17 & Baik \\
\hline Pemilihan ranah penilaian & 62,50 & Baik \\
\hline Rata-rata & 75,70 & Baik \\
\hline
\end{tabular}

Berdasarkan data pada Tabel 3, rata-rata kemampuan PK mahasiswa calon guru Biologi dari enam indikator/kriteria adalah 75,70\%. Artinya, calon guru Biologi memiliki kemampuan/kompetensi pedagogik yang baik. Penggunaan metode/model dalam RPP yang disusun oleh mahasiswa calon guru biologi memperoleh persentase skor sebesar 91,67 (Sangat Baik). Mahasiswa calon guru mampu untuk menentukan atau memilih metode/model pembelajaran yang tepat sesuai dengan materi atau tujuan yang akan dicapai. 
Penggunaan metode/model hanya memperoleh skor sebesar 75\%, hal tersebut disebabkan mahasiswa belum menggunakan metode atau model yang bervariasi, serta masih ditemui kekeliruan dalam mengimplementasikan langkah atau fase dari model pembelajaran yang dipilih. Jenis media pembelajaran memperoleh skor terendah pada kemampuan PK, yaitu 58,33\% (cukup). Hal tersebut disebabkan karena umumnya mahasiswa masih terfokus pada penggunaan media power point atau hanya mengandalkan satu jenis media saja, meskipun ada yang melengkapi dengan media lain.

Pengetahuan tentang pemilihan media yang sesuai dengan kegiatan pembelajaran memperoleh skor 87,59\% (Sangat Baik). Hal tersebut dikarenakan mahasiswa calon guru dapat menyesuaikan media yang digunakannya sesuai ruang lingkup materi, jumlah siswa, serta kemudahan dalam penggunaan media. Ibrahim dan Syaodih (2003) menyatakan ada beberapa faktor yang perlu diperhatikan dalam memilih media yang tepat yaitu: (1) jenis kemampuan yang akan dicapai, apakah sesuai dengan tujuan pengajaran; (2) kegunaan dari berbagai jenis media itu sendiri; (3) kemampuan guru menggunakan suatu jenis media; (4) keluwesan atau fleksibilitas dalam penggunaannya, artinya seberapa jauh media tersebut dapat digunakan dengan praktis dalam berbagai situasi dan mudah dipindahkan dari satu tempat ke tempat lain; (5) kesesuaian dengan alokasi waktu dan sarana pendukung yang ada; (6) ketersediaannya; dan (7) biaya.

Indikator menyusun alat evaluasi memperoleh kategori baik $(79,17 \%)$. Hal tersebut dibuktikan dengan kemampuan calon guru dalam menyusun alat evaluasi yang meliputi teknik penilaian, jenis tes, dan jumlah soal yang disesuaikan dengan tujuan serta waktu di akhir pembelajaran. Namun masih ditemukan adanya soal yang tidak sesuai dengan kaidah penulisan soal seperti pengecoh yang tidak berfungsi serta soal yang bermakna ambigu. Sedangkan untuk soal esai atau uraian masih dijumpai kekeliruan dalam memberikan skor.

Pemilihan ranah penilaian memperoleh skor 62,50\% (Baik). Hal tersebut disebabkan mahasiswa calon guru sebagian besar masih membuat penilaian ranah 
kognitif. Ranah afektif dan psikomotor sudah dicoba oleh mahasiswa namun masih dirasa sulit terutama jika harus membuat rubrik untuk penilaian psikomotor. Suryawati, dkk. (2014) mengungkapkan bahwa kompetensi pedagogik atau PK penting ditanamkan pada mahasiswa calon guru dalam rangka mempersiapkan dan membekali diri agar dapat mengelola pembelajaran dengan baik.

\section{Kemampuan PCK Mahasiswa Calon Guru Biologi}

Kemampuan PCK merupakan kemampuan memadukan pengetahuan konten dan pedagogik yang meliputi kesesuaian materi dengan metode/model dan evaluasi. Dalam penelitian yang diukur adalah keterampilan mahasiswa calon guru dalam melaksanakan pembelajaran lewat kegiatan pendahuluan, inti, dan penutup.

Tabel 4 Data Kemampuan PCK Calon Guru Biologi dalam Menyusun RPP

\begin{tabular}{lcc}
\hline \multicolumn{1}{c}{ Penilaian } & \% & Kategori \\
\hline Kegiatan Pendahuluan & 62,50 & Baik \\
Kegiatan Inti & 62,50 & Baik \\
Kegiatan Penutup & 75,00 & Baik \\
\hline \multicolumn{1}{c}{ Rata-Rata } & $\mathbf{6 6 , 6 7}$ & Baik
\end{tabular}

Berdasarkan data pada Tabel 4, terlihat bahwa kemampuan PCK mahasiswa calon guru Biologi termasuk kategori baik (66,67\%). Hal tersebut ditunjukkan dengan kemampuan kegiatan pendahuluan 62,50\% (baik), kemampuan kegiatan inti 62,50\% (baik), dan kemampuan kegiatan penutup 75,00\% (sangat baik).

Berdasarkan hasil dokumentasi dari RPP yang disusun oleh mahasiswa calon guru terlihat pada kegiatan pendahuluan, apersepsi yang dituliskan belum sepenuhnya sesuai dengan tujuan atau materi yang akan dibahas. Apersepsi yang mahasiswa susun masih terlalu lebar, tidak menjurus ke materi, dab masih ada 
yang tidak mencantumkan penyampaian tujuan pembelajaran. Menurut Trowbridge, et al. (Anggraeni, 2009) membuat tujuan pembelajaran yang baik sangat penting, tanpa tujuan pembelajaran akan menjadi tidak terarah, membingungkan dan membuat frustasi bagi guru serta tidak efektif bagi siswa. Sedangkan Margiyono (2011) menyatakan bahwa tujuan pembelajaran dimaksudkan agar siswa mengetahui apa yang akan dipelajari dan fokus dalam belajar.

Pada kemampuan kegiatan inti, diperoleh rerata skor sebesar 62,50\% dengan kategori baik. Mahasiswa calon guru sudah melibatkan siswa secara aktif sesuai dengan model pembelajaran dan pendekatan saintifik yang digunakan. Namun, masih ada beberapa diantaranya terlihat bingung ketika mengimplemantasikan model Problem Based Learning (PBL). Sedangkan pada kegiatan penutup memperoleh persentase tertinggi yaitu 75,00\% kategori baik. Hal tersebut dikarenakan semua komponen dalam kegiatan penutup telah dituliskan, namun masih perlu latihan untuk alokasi waktu setiap komponen. Secara keseluruhan, kemampuan PCK mahasiswa calon guru sudah baik, namun perlu dilatihkan lagi untuk kemampuan kegiatan pendahuluan dan kegiatan inti.

Berdasarkan pembahasan yang telah diuraikan, kemampuan pedagogical content knowledge (PCK) mahasiswa calon guru Biologi yang dilihat dari aspek CK, PK, dan PCK sudah berada pada kategori baik namun dirasa masih perlu ditingkatkan. Oleh karenanya, mahasiswa calon guru perlu dibekali kemampuan PCK terutama dalam penyusunan RPP yang memadai sebelum praktik langsung di sekolah dengan memaksimalkan perkuliahan yang mendukung.

\section{SIMPULAN}

Berdasarkan hasil penelitian dan pembahasan dapat disimpulkan bahwa kemampuan pedagogical content knowledge (PCK) mahasiswa calon guru dalam menyusun RPP termasuk kategori baik $(71,06 \%)$ yang ditunjukkan dengan 
kemampuan CK baik (70,83\%), kemampuan PK baik (75,70\%), dan kemampuan PCK baik $(66,67 \%)$.

\section{UCAPAN TERIMA KASIH}

Terima kasih kepada FKIP Universitas Tanjungpura yang telah memberikan dana PNBP untuk kegiatan penelitian serta pihak yang telah membantu pelaksanaan penelitian.

\section{DAFTAR PUSTAKA}

Anggraeni, S. 2009. Sudahkan Calon Guru Biologi Merencanakan Pembelajaran Biologi yang Sesuai dengan Hakikat Sains. Prosiding Seminar Nasional Penelitian, Pendidikan dan Penerapan MIPA. Universitas Negeri Yogyakarta tanggal 16 Mei 2009.

Anwar, Y. 2014. Kemampuan Pedagogical Content Knowledge Guru Biologi yang Berpengalaman dan yang Belum Berpengalaman. Jurnal Pengajaran MIPA, 19(1): 1412 .

Hamidah, D., Nuryani, Y., \& Made, A. M. 2011. Pengembangan Profesional Guru Biologi SMA melalui Penerapan Pedagogical Content Knowledge (PCK) pada Materi Genetika. Jurnal Pendidikan IPA, 12(2): Oktober 2011.

Hamzah. 2008. Model Pembelajaran. Jakarta: Bumi Aksara.

Ibrahim \& Syaodih, N. 2003. Perencanaan Penganjaran. Jakarta: Rineka Cipta.

Loughran, J., Amanda, B., \& Pamela, M. 2006. Understanding and Developing Science Teacher's Pedagogical Content Knowledge. Australia: Senshe Publisher.

Margiyono. 2011. Pengembangan Profesi Guru. Jakarta: Rajawali Press.

Rosnita. 2011. Standar Pendidikan untuk Calon Guru Sains: Pedagogi Materi Subjek sebagai Sarana Pengembangan Content Pedagogi Calon Guru. Jurnal Cakrawala Kependidikan, 9(2). 
Suryawati, E., Firdaus,, L. N., \& Yosua, H. 2014. Analisis Keterampilan Technological Pedagogical Content Knowledge (TPCK) Guru Biologi SMA Negeri Kota Pekanbaru. Jurnal Biogenesis, 11(1): 67-72.

Widiyoko, E. P. 2013. Evaluasi Program Pembelajaran. Yogyakarta: Pustaka Pelajar. 